\title{
Jovens e Associações em Moçambique: motivações e dinâmicas actuais
}

\section{Youths and Associations in Mozambique: motivations and current dynamics}

\author{
Adriano Mateus Biza \\ Mestrado em Antropologia e Sociologia Críticas do Desenvolvi- \\ mento. Professor Assistente no Departamento de Arqueologia e \\ Antropologia da Universidade Eduardo Mondlane. \\ Endereço: Departamento de Arqueologia e Antropologia, Facul- \\ dade de Letras e Ciências Sociais, Campus Universitário Principal, \\ Caixa Postal n. 257, Maputo, Moçambique. \\ E-mail adriano.bizaळuem. $\mathrm{mz}$
}

Resumo

O presente artigo é uma reflexão sobre dinâmicas associativas de jovens no Moçambique pós colonial. O objectivo desta reflexão foi identificar e analisar as motivações de engajamento dos jovens nesses agrupamentos. Baseando-se em aproximações empíricas feitas a duas associações de jovens - Associação Aro Juvenil e Associação Positiva Juvenil - a análise demonstra que dinamica associativa de jovens mete em evidência relações complexas entre identidade, contexto, o privado, o público e o afectivo. Embora haja múltiplas motivações, a adesão dos jovens em associações associa trajectórias e expectativas individualizadas. A nível discursivo, a entrada na vida associativa representa uma forma de legitimação sóciopolítica em resposta a um discurso que considera os jovens passivos e pouco intervenientes na solução dos problemas que lhes afecta em particular e à sociedade no geral. A nível das práticas associativas quotidianas, os jovens reintrepretam e dão outro sentido às motivações do seu engajamento: para lá dos objectivos formais, pretensamente desenvolvimentistas, altruistas e humanitários, o associativismo é uma estratégia de vida e de realização de projectos individuais. Criar uma associação e/ou nela aderir pode significar maiores possibilidades de aceder e controlar recursos e capitais diversificados como emprego/profissão, dinheiro, trabalho, poder, reconhecimento e prestigio, formações entre outros que de outra forma não seria possível.

Palavras-chave: Jovens; Dinâmicas associativas; Motivações de engajamento; Papéis e Capitais. 


\section{Abstract}

This article reflects on youth associations dynamics in Postcolonial Mozambique. The aim is to identify and analyze motivations for young people's involvement in such groups. Based on empirical work with two youth associations - namely "Associação Aro Juvenil" and "Associação Positiva Juvenil" - the assessment finds that youth associations dynamics highlights intricate relationships involving identity, context, private, public and affective milieus. Although there are multiple motivations, young people's adherence to associations is combined with individual life stories and expectations. At the discourse level, entrance to the associative life represents a form of socio-political legitimation in response to other narratives that consider young people very passive and less intervening in finding solutions to their own problems, and society's in general. At the level of day-to-day practices, young people re-interpret and give a different sense to their motivations and commitment: beyond formal objectives - arguably development-oriented, altruistic and humanistic - associations are a life strategy for the accomplishment of individual achievements. To create an association and/or take part in one may imply greater possibilities of accessing and controlling diversified resources and capitals, such as a job/occupation, money, work, power, recognition, prestige, and training, among others, which would be otherwise impossible.

Keywords: Young People; Association Dynamics; Motivations for Engagement; Roles; Capitals.

\section{Introdução}

Em Moçambique, o final da década go é marcado por uma explosão de associações juvenis de carácter cultural e recreativo, sóciohumanitárias, religiosas, estudantis e políticas partidárias (em forma de ligas juvenis), a maior parte concentrada nos centros urbanos (Manjante, 2001). Este crescimento na criação de associações está associado às mudanças sóciopolíticas que o país vem vivendo nas últimas duas décadas. País independente em 1975, Moçambique adoptou o monopartidarismo de inspiração socialista e de ideologia marxista-léninista como identidade do seu sistema político, reconhecido oficialmente em 1977. Nos anos 8o, o país é confrontado por uma crise sócioeconómica intensificada pela guerra civil iniciada um ano depois da proclamação da independência; tendo por isso iniciado reformas tais como a liberalização económica e política. A liberalização económica traduziu-se na adopção do Programa de Reabilitação Económica (PRE), adoptado pelo governo em 1987, enquanto que a política se manifestou pela tendência de abertura do sistema político em direcção ao multipartidarismo, processo coroado pela adopção do novo texto constitucional em 1990, que inaugurava o respeito aos direitos individuais, a livre expressão, o direito à associação e a consequente abertura de novos espaços de participação na vida pública.

Ao mesmo tempo que se constatava a tendência crescente de organizações de jovens com várias iniciativas em diferentes domínios de actividades, ocorre um processo de discussão nas diferentes esferas da sociedade moçambicana sobre a participação da juventude moçambicana no processo de desenvolvimento do país. As críticas relevantes são em volta das reais motivações do associativismo juvenil, em relação ao papel efectivo desempenhado por estas organizações e ao impacto das actividades por elas desenvolvidas para atingir os objetivos formalmente anunciados. No concreto da crítica, as actividades e programas nos quais as suas acções se inscrevem são considerados isolados, desarticulados e sem seguimento; as associações de jovens são consideradas éfémeras e não representativas de grande parte dos estratos da juventude moçambicana e; estas organizações são também criticadas na medida em que o seu activismo é visto como beneficiando somente os seus membros em detrimento dos destinatários e gru- 
pos alvos anunciados nos seus estatutos e programas de acção (Manjante, 2001, p. 21-30).

O presente artigo é uma reflexão sobre dinâmicas associativas de jovens no Moçambique pós colonial. O objectivo desta reflexão foi de identificar e analisar as motivações de engajamento dos jovens nesses agrupamentos e o papel desempenhado por estes, baseando-se em dados empíricos de duas associações caso, Associação Aro Juvenil e Associação Positiva Juvenil. A temática é pertinente porque há pouca produção académica sobre esta categoria social em contexto moçambicano. As escassas reflexões sobre os jovens ocorrem associadas à análise dos problemas sociais, onde estes são vistos como produtores de fenómenos de anomia social como o crime, a violência e deliquência. Por outro lado, está na ordem de dia um discurso que apela e mobiliza os jovens a associar para melhor participar no processo de desenvolvimento do país.

A reflexão é inspirada pelas abordagens sobre a juventude surgidas nos anos 90 na literatura sócioantropológica, cujo pesquisas mostraram o carácter e a situação ambígua que caracterizam os jovens africanos: para além da sua imagem de destruidores, de figuras centrais da guerra, da violência e de outros males sociais que atingem a maioria destas sociedades; os jovens são também vistos como actores constructores, uma força social emergente e que constitui hoje parte integrante da configuração das sociedades africanas, que não pode ser neglenciada na comprensão das mudanças que estas sociedades passam (Honwana e De Boeck, 200o, p. 5-11). Em consonância com estas abordagens, a reflexão distancia-se do ponto de vista simplista e generalizado que vê nos jovens actores passivos e vítimas da manipulação dos adultos e da sociedade, mas concebe-os como actores agenciadores com possibilidades de criar espaços de engagamento e agir em tanto que indivíduos ou grupos para assegurar a sua participação e a sua legitimação a partir da leitura e consideração que fazem da sua experiência social e dos constrangimentos aos quais se confrontam no quotidiano (Idem).

\section{Génese e Desenvolvimento das Associações Juvenis}

O interesse pelos processos de constituição de grupos não é nova na literatura sócioantropológica. Segundo
Fillieule e Péchu (1993) questionar sobre as condições da emergência das acções colectivas implica fazer o inventário das oportunidades políticas que permitem que uma acção colectiva seja possível e também as circunstâncias diversas que terão fornecido o quadro das possibilidades para que tal acção ocorra. No contexto de análise das organizações significa distinguir o papel desempenhado pelos factores contextuais e pontuais, pelas condições internacionais, nacionais e locais (Sardan, 1998, 23-27).

Agénese das associações de jovens em Moçambique é diversificada. Embora a génese seja diversificada, são notáveis referências comuns: aparecem como redes de indivíduos e pequenos círculos sociais surgidos nas igrejas, escolas e bairros onde os jovens habitam; mais tarde estes transformam-se em agrupamentos institucionalizados à procura de reconhecimento ou dos poderes públicos ou dos organismos doadores que querem os apoiar. A institucionalização destes agrupamentos associativos segue quase o mesmo modelo, o encorajamento feito pelo Estado e ONGs internacionais.

Embora não exista um modelo único sobre a vocação destas associações, a tendência global é que estas apostam na pluriactividade: emergem como grupos envolvidos em movimentos culturais e recreativos e mais tarde se tornam organizações desenvolvimentistas no sentido em que postulam ideias de transformação do meio sócioeconómico em que estão envolvidos, agindo na interface entre os doadores e o público alvo das suas intervenções, em áreas temáticas hegemónicas nas agendas e mercado da ajuda ao desenvolvimento, nomeadamente formação e integração social, promoção da equidade de género, HIV e SIDA, direitos humanos, entre outros.

A Associação Positiva Juvenil foi criada por um grupo de jovens cristãos de diferentes igrejas protestantes, sobretudo as igrejas Assembleia de Deus (pentescostal) e Presbiteriana de Moçambique (Paróquia de Khovo). Estes jovens faziam parte da pastoral da juventude, designação dada aos pequenos grupos de jovens que são formados em cada igreja, reunidos em volta de actividades de cântico, dança e sensibilização moral e ética sobre vários temas de interesse da sociedade. Foi então nestes encontros e eventos organizados que surgiu a ideia de se criar uma associação juvenil. Inicialmente foi constituido o núcleo activo fundador e a 
ideia da associação expandiu-se pelas escolas e bairros onde os membros fundadores estudavam e habitavam para atrair os colegas de escola e vizinhos, sobretudo nos bairros periféricos da Malhangalene e Maxaquene. É preciso sublinhar que a identidade regligiosa, a amizade, a vizinhança, e todo o tipo de relações sociais prexistentes entre os membros fundadores e o conjunto dos jovens afiliados foram essenciais para criar o núcleo central que dinamizou a constituição da associação formal como ela é conhecida na actualidade.

Por sua vez, a associação Aro Juvenil nasceu como um movimento literário promovido por jovens alunos da cidade do Maputo que se conheciam anteriormente. A Aro Juvenil surgiu como um núcleo de alunos de duas escolas, a Escola Secundária Francisco Manyanga e a Escola Industrial $1^{\circ}$ de Maio, em 1993. 0 objectivo central do núcleo era criar e dinamizar um movimento literário, principalmente a criação de um boletim literário, a promoção de concursos de escrita e declamação de poemas, assim como a fundação à posterior da Associação Moçambicana de Jovens Escritores (AMOJE), tendo estes se transformado no Núcleo Juvenil da Associação dos Escritores Moçambicanos (AEMO).

Relatos de membros fundadores revelam que foi na condição de núcleo juvenil da AEMO que estes jovens conseguiram lançar o primeiro boletim literário designado por "Aro Jvernil" a 11 de Fevereiro de 1994 e que foi editado durante três anos. Para além da edição e publicação deste boletim, o núcleo de jovens organizava quinzenalmente eventos culturais de exibição de peças de teatro, concertos de música e debates sobre temas que inquietavam a juventude. Doravante, a Aro Juvenil constituiu-se numa associação juvenil por deliberação dos seus membros durante a Conferência Nacional que teve lugar na Beira em Julho de 1997. Constituida como primeira associação de jovens, a organização transforma-se em contraparte local de ONGs internacionais com intervenções dirigidas a jovens, no campo temático da saúde sexual e reprodutiva e HIV/SIDA, mudando de vocação da literatura para os projectos de desenvolvimento.

\section{A Identidade dos Jovens Associados}

A reflexão procurou identificar varíaveis demográficas e sociológicas que fornecessem informação sobre a identidade dos jovens que se associam. Existem diferenças de participação nas associações de jovens em função do nível de instrução, gênero, ocupação, e espaço de residência. As causas destas características são complexas que uma pesquisa exporatória não os pôde determinar. No entanto, ficou mais saliente que o grau de instrução, as diferenças de participação entre jovens no campo e na cidade e entre jovens do sexo masculino do sexo feminino constituem o dado mais significativo sobre a identidade e característica essencial do fenómeno associativo nos jovens.

$\mathrm{Na}$ totalidade das associações pesquisadas, foi observado que são os jovens alfabetizados e sobretudo urbanos, ou ainda em contacto permanente com a cidade, que criam e constituem-se membros das associações. Esta situação pode explicar-se parcialmente pelo facto de que os mecanismos que favorecem a participação na esfera pública - o acesso à informação de natureza jurídica e política (também sobre os financiamentos) e que tornam os indivíduos como sujeitos de direito, cidadãos e responsáveis pelo destino das suas próprias vidas - encontram-se limitados àqueles que tiveram acesso à escola, um espaço com potencialidades para edificar uma sensibilidade cívica e política. Neste sentido, quanto mais o jovem é socialmente excluido e não escolarizado, menores possibilidades e oportunidades tem de participar na vida pública através do activismo associativo; o que faz do jovem rural, um actor esquecido e quase invisível na esfera pública.

No que concerne à ocupação, a maioria dos jovens que fazem parte das associações são alunos do ensino geral ou técnico. Fazem parte igualmente estudantes universitários, sobretudo os líderes das associações. Pelo facto de serem estudantes, estes jovens membros dividem a sua vida e tempo entre dois espaços sociais: os que vão à escola de manhã, pela tarde passam pela associação e vice-versa; ou ainda passam todo o dia na associação. Encontram-se ainda jovens que estão o tempo inteiro na associação frequentando a escola no período nocturno.

Foi possível identificar três sub-categorias de jovens nas associações. Estas categorias estão associadas às trajectorias individuais, às modalidades de adesão às associações, assim como às suas motivações. Nas associações encontram-se jovens escolarizados (alunos) que dividem parcialmente o seu tempo entre a escola e a associação; os jovens escolarizados mas desempregados que estão o tempo inteiro na associação e que "vivem da associação» como eles próprios 
afirmam, e cujo engajamento associativo representa uma oportunidade de ocupação até mesmo de emprego; e uma terceira sub-categoria de pequenos profissionais/trabalhadores das associações que realizam tarefas administrativas e auxiliares. Estes últimos entraram para a associação para trabalhar, mas porque se encontram num contexto de afiliações, tornaramse posteriormente membros. Esta forma de adesão, digamos técnica e/ou profissiional, está na maior parte dos casos associada a imperativos de aumento do número de membros, o que pode dar uma imagem de tamanho e por consequência da legitimidade da própria associação.

Outra característica importante da identidade dos associados é o facto de a adesão a estas organizações constituir apanágio de jovens do sexo masculino. 0 índice global dos membros nas associações é elevado para jovens do sexo masculino em detrimento dos jovens do sexo feminino. Segundo os próprios associados, são as representações sócioculturais e simbólicas que a sociedade constrói, o papel e posição atribuidos à mulher bem como o rígido controle social familiar sobre as jovens do sexo feminino, que explicam as diferenças de participação entre rapazes e raparigas nas associações. Neste contexto, a associação reproduz e pereniza o modelo patriarcal que caracteriza as sociedades africanas e que tende a acantonar as mulheres e raparigas no espaço doméstico.

No entanto, é preciso realçar que a constatação de uma diferença de adesão e participação em associações entre raparigas e rapazes não pode conduzir a inferir sobre a existência de um "carácter feminino" que predetermina os jovens do sexo feminino a participar menos que os seus contrários; ou ainda considerar que há uma "masculinização" do espaço associativo. O fenómeno é mais complexo e uma explicação sociológica destas diferenças necessita de uma pesquisa aprofundada sobre os mecanismos sociais, simbólicos, ideológicos e contextuais da produção das diferenças e das desigualdades entre os homens e as mulheres; uma tarefa que não constituiu o objectivo desta reflexão.

Por outro lado, acreditando-se nas virtudes emancipadoras da adesão e participação em associações, poder-se-ia inferir que a entrada dos jovens do sexo feminino nas associações poderia deste modo servir de canal para contornar as regras de funcionamento da sociedade global. No entanto, os dados empíricos sugerem que o espaço das associações é também uma forma de continuidade da "dominação masculina", na medida em que as poucas raparigas que se encontram nas associações reservam-se ou são lhes reservadas tarefas tradicionalmente consideradas como as menos valorizadas, menos complicadas ou mesmo menos pesadas e, por causa disso, "tipicamente" femininas, como estar na recepção, ser secretária, preparar e enviar documentos e a correspondência entre outros papeis auxiliares.

Por último, existe uma estreita correlação entre o meio socio-espacial urbano e o fenómeno associativo. As criações de associações são mais numerosas nas cidades ou nos grandes centros urbanos. Mesmo para o caso de associações que obtem a sua legitimidade no apoio a estratos desfavorecidos da juventude rural, são os jovens urbanos que vão às aldeias para implementar tais actividades. Existem muitas explicações sobre a relação entre o meio urbano e o número de associações. Para alguns autores, o facto associativo desenvolve-se melhor onde duas condições estão reunidas: por um lado, a dissolução relativa dos grupos primários de sociabilidade; e por outro, uma insuficiente integração social que predispõe os actores sociais a formarem agrupamentos especializados e que permitem aos indivíduos identificarem-se num determinado espaço sociogeográfico (Barthelemy, 2002, p. 68).

É necessário sujeitar estes dados à prova do contexto: primeiro, estudos precedentes realizados no contexto africano e mesmo moçambicano demonstraram que nem sempre o meio urbano conduz à desestructuração total e/ou dissolução dos grupos e rede de relações primários. Pelo contrário, em função das vicissitudes do contexto sócioeconómico, muitas das vezes crítico e incerto, os grupos primários e as sociabilidades recriam-se, reinventam-se e solidificam-se (Loforte, 1996). Por outro lado, para os jovens são estes canais, pertenças e sociabilidades prexistentes que fundam a especificidade do seu fenómeno associativo, sobretudo das modalidades da sua adesão, como se expõe de seguida.

\section{Das Modalidades e Lógicas de Adesão Associativa}

Como é que os jovens aderem às associções ? De uma maneira geral, a adesão dos jovens às associações tem uma relação estreita com as suas trajectórias 
individuais, com o contexto sócioeconómico no qual estão inseridos e com o seu potencial em estabelecer redes de sociabilidade. Embora a prática revele uma pluralidade de formas de adesão nas associações, o traço mais comum é que a entrada numa associação é socialmente determinada pelos laços préxistentes e não pela potencial identificação com os objectivos da associação constante nos estatutos. São estes laços que revelam em relação a quem e em relação a quê o jovem adere e se envolve nas associações.

\section{A Associação é uma Família: o papel das redes primárias de sociabilidade}

A sociabilidade está no centro do processo de entrada e de contacto dos jovens com o espaço associativo e as duas associações estudadas são reveladoras deste dado. Nelas foi observado que a existência de laços de parentesco e o conhecimento interpessoal prévio entre os membros constituem factor determinante para a adesão. Pequenas diferenças existem entre as duas associações mas que se relacionam com as trajectórias individuais dos membros em cada uma delas; contudo, o processo de edificação de laços com outrem, os investimentos relacionais que se operam de uns para com os outros são capitais.

As interações quotidianas entre parceiros, colegas, amigos e vizinhos são (re)apropriadas pelos jovens para criar identificações mútuas na esfera pública. As redes sociais primárias são as que mais se destacam neste processo. A entrada numa associação é limitada aos conhecidos, sejam eles amigos, parentes próximos (o caso de irmãos) e vizinhos, o que evidencia o papel estruturante da sociabilidade e a sua posição de dimensão incontornável para compreender como os jovens entram nas associações. O caso da APOJ é o mais ilustrativo neste contexto porque ela é vista pelos seus membros como se fosse uma família:

“...consideramos a APOJ Uma familia porque apesardo nosso estatuto de membros, todos são companheirose nos conhecemos; foram aproximações por amizade... mesmo se outros entraram porverem o que faziamos, sempre tivemos uma ligação: ou somos amigos ou vivemos no mesmo bairro ou estudamos juntos...".

Se a sociabilidade é reveladora das modalidades de entrada dos jovens nas associações, é certo também que ela é paradoxal; por um lado, há uma liberdade formal de aderir na associação a partir do momento em que há identidade com os seus objectivos; mas por outro lado, exclui-se pela natureza dos laços existentes entre os que já fazem dela. Não se entra em relação com qualquer um, as redes de sociabilidde são de certa maneira e muitas vezes homogêneas. Consequentemente, a livre adesão está também de certa forma limitada ao círculo dos companheiros ou amigos, e os próprios jovens associados já interiorizaram estes mecanismos porque eles aproximam-se das associações onde há pessoas que lhes são próximas ou a quem se assemelham sob o ponto de vista sociológico. Deste modo, as relações de amizade, de colegas e de vizinhança encontram-se submetidas à lógica de divisão e classificação que atravessam completamente a sociedade (Bidart, 1999, p. 7).

Foi observado que entre os difrentes tipos de laços que determinam a entrada nas associações, a amizade desempenha um papel igualmente preponderante : “... a associação não se forma por acaso, são as relações de amizade que contam, há poucas pessoas que nada têm a ver umas com as outras"(Membro da APOJ). A amizade é definida a partir da proximidade social. Segundo Claire Bidart, a escolha e definição de amigos não se opera ao acaso, as redes dos amigos são mais ou menos homogêneas e há mecanismos sociais que presidem esta homogeneização. Existe uma tendência global de as amizades se formarem por volta de preferências sociais e desta forma se orientarem no sentido de semelhança social, ou seja, uma tendência para se formar entre indivíduos que se parecem em termos de status sociais (Bidart, 1997, p. 42). Estas tendências encontram-se também nos jovens que se associam, onde há também preferências entre os que são convidados a se juntar às associações.

Das falas com os jovens pode-se constatar que a maioria dos jovens tomou conhecimento das associações em que estão hoje inseridos por via de um (a) amigo (a), colega de escola ou vizinho já filiado. Ora, o facto de fazer parte destes círculos sociais não é por si só garantia de uma entrada, digamos automática no agrupamento, é preciso primeiro um “convite”. É necessário sublinhar não são todos os amigos, vizinhos, colegas que são convidados; há, em última análise, limites no papel desempenhado por estas sociabilidades. Estes limites estão associados à natureza específica de certos laços: entre os amigos há os que são mais amigos que os outros e na prática as pessoas associam-se com "pessoas como nós", do mesmo nível, com a mesma educação e do mesmo meio social. 


\section{A adesão técnica e administrativa}

A segunda mais significativa modalidade de entrada na vida associativa é aquela que diz respeito aos jovens que entraram justamente para se puder cumprir com os requisitos, procedimentos e normas jurídicas e administrativas, tanto para a legalização e reconhecimento das associações, como para aumentar a legitimidade da organização em relação ao resto da sociedade, extendendo a sua cobertura para outros pontos do país.

Para o primeiro caso, os discursos dos jovens associados indicam que aderiram à associação para completar o número de associados que os regulamentos e leis relativas ao registro das associações exigiam, sobretudo na fase do começo da organização que impõe o mínimo de membros fundadores. Como a maioria das associações começou com pouco associados, há dado momento que pela necessidade da oficialização e reconhecimento, elas tiveram a necessidade de atrair mais jovens. E mesmo aqui as redes de sociabilidade foram determinantes, o convite priorizou aqueles jovens socialmente próximos e com os quais já se mantinham relações interpessoais prévias, como se evidencia neste discurso:

“...primeiro a ideia [de criar a associação] veio de um grupo de cinco pessoas; até ao registo público já eramos dez...eu entrei um pouco mais tarde, no momento em que se preparava a documentação para o registro da associação. Fui convidado por um amigo, o ex-presidente da associação, que me perguntou se não estava interessado em fazer parte de uma associação de jovens que apoiam jovens desfavorecidos. Eu não tinha nenhuma ideia do que era uma associação mas concordei, entreguei documentação e assinei a lista dos membros para a sua aprovação...”.

A adesão associativa para colmatar exigências administrativas de reconhecimento e oficialização não é a única forma do que se considera adesão técnica. Esta modalidade de entrada é de natureza dupla, existe igualmente um conjunto de jovens que entram nas associações como trabalhadores e que mais tarde, por necessidade de acréscimo do número de associados, entre outros motivos, tornaram-se membros das associações.

Os dados descritos acima revelam que existe uma cumplicidade entre as pertenças colectivas vividas previamente e sua forma de adesão às associações evidencia que a dinâmica associativa no seio dos jovens põe em evidência relações complexas entre a identidade, o contexto, o privado, o público e o afectivo. É esta cumplicidade entre a trajectória individual e o contexto que também revela para quê os jovens se associam.

\section{As razões do engajamento dos jovens nas asso- ciações}

Porquê os jovens se engajam em associações e qual é o sentido que eles dão a esta acção? A literatura sobretudo nos países ocidentais mostra que as associações são fundadas e organizadas em volta de objectivos e projectos a longo prazo ou duradoiros (Caillé, 1998; Laville, 1998; Sainsaulieu, 1996). Autores há que discordaram com o caracter generalizantes desta acepção a todos os grupos que se associam. Estes revelaram que, pelo contrário, na actualidade e mesmo nesses contextos, os cidadãos e mais particularmente os jovens aderem a uma associação porque se interessam por uma acção específica - e consequentemente têm motivações específicas - limitada no tempo e no espaço e que se espera que tenha resultados concretos imediatos (Gillet, 2001). Os jovens só continuam com a participação se eles estiverem satisfeitos com os resultados e se interessarem pela etapa seguinte, se não, eles desistem. Ninguém duvida que seja uma abordagem estratégica.

Para os jovens, é mais o "pragmatismo" que o "idealismo" que dá mais sentido a sua adesão nas associações. A literatura sobre o mesmo fenómeno noutros contextos, sobretudo ocidental, tinha mostrado que a estruturação das associações se faz em volta de uma identidade partilhada e que a participação nessas actividades significava contribuir para a realização de uma obra colectiva. 0 discurso dos jovens recolhido sobre as motivações da sua adesão ao associativismo não afasta esta dimensão da acção, como o provam as actividades realizadas pelas associações objecto de reflexão. Todavia, a contribuição para a realização de uma obra colectiva constitui uma das dimensões explícitas das motivações do engajamento associativo dos jovens, também ligada à necessidade da legitimação da acção associativa. Trata-se de uma situação que vai ao encontro daquilo que foi referido por alguns autores: a finalidade com vista a objectivos colectivos ocorre em paralelo com uma tendência à realização de objectivos pessoais e individuais, o que ilustra uma 
tendência de se passar de engajamentos duradoiros a engajamentos contratuais e efémeros (Perrineau, 1994; Roudet, 1996).

De forma geral, as motivações da adesão dos jovens às associações estão subordinadas às suas expectativas individuais. As razões de entrada no espaço associativo estão relacionadas à diferença existente entre o seu campo de experiência e o seu horizonte de expectativas. Os jovens apercebem-se cada vez mais que o mundo social no qual estão inseridos revela-se doravante incapaz de realizar as suas aspirações e projectos individuais. Como consequência, os jovens associam-se por " razões práticas », e estas são razões ligadas às situações que eles enfrentam no seu quotidiano. 0 contexto de dificuldades sociais e económicas que afecta a parte significativa deles, impele-os a entrar no activismo e encarar o associativismo numa abordagem estratégica que visa não somente solucionar problemas das privações, mas também obter reconhecimento social, num contexto em que os mesmos jovens são frequentemente confrontados com discursos que fazem referência à sua passividade e apatia.

0 engajamento associativo visto numa abordagem estratégica significa que, pela entrada nas associações, os jovens demonstram o seu sentimento de dedicação para com outrem; eles preparam o seu próprio futuro; eles passam de uma atitude de expectativa para uma atitude de conquista e de criação e; eles procuram resolver colectivamente as incertezas do momento.

Das observações feitas em contacto com as organizações, foi possível identificar a natureza das motivações do engajamento associativo dos jovens. Primeiro, encontra-se com mais frequência no discurso dos jovens a referência aos obejctivos altruistas, que se traduzem por uma forte manifestação de sentimentos e disposição para se interessar e se sacrificar por outrem. Aqui, a entrada na vida associativa é manifestação da sensibilidade moral e humanitária. Os jovens associam-se ou engajam-se nas associações para "ajudaros outros", sejam da sua aldeia ou de qualquer outro lugar da sociedade onde haja desfavorecidos, jovens ou adultos. Para alguns deles, como foi referido, este carácter altruista e/ou sensibilidade para se sacrificar por outrem foi construido em meio religioso, ao qual pertenciam, antes mesmo de fazer parte da associação, considerando as trajectórias individuais assim como a sóciogénese destes agrupamentos.
Existem diferentes domínios e sectores onde os jovens investem-se em acções colectivas altruistas. A motivação altruista é de carácter solidário e humanitário em relação à colectividade, mas também pode estar virada para eles mesmos. Os jovens engajam-se por causas sociais mais vastas de entreajuda pública, em temáticas como do meio ambiente e dos direitos humanos, mas também quando se sentem particularmente implicados. Neste caso, eles engajam-se ou "para fazer chegar a mensagem sobre a prevenção contra a doença do HIV/SIDA às camadas desfavorecidas e vulneráveis", ou ainda "para combater os males da sociedade afastando os jovens da droga e do álcool", ou mesmo para "combater a pobreza", no sentido mais lato da palavra.

Uma das características fundamentais das dinâmicas associativas, é que a entrada nas associações é encarada como uma etapa essencial para a inserção profissional dos jovens. Para estes, cuja maioria não está diplomada, ou está a seguir os estudos, a entrada nas associações pode ser determinante para o futuro individual, uma espécie de trampolim para o seu futuro profissional. Neste contexto, engajar-se numa associação representa uma oportunidade de encontrar um emprego e/ou lutar contra o desemprego que afecta esta categoria social. Num contexto em que o Estado se desengaja cada vez mais das suas responsabilidade sociais, o desafio da procura de um meio profissional faz da entrada na associação um mecanismo de passagem de uma atitude passiva, de espera de um futuro melhor dado, a uma atitude activa, mais de conquista e criação.

A passagem de uma atitude passiva para a activa, mesmo se for um acto que diz respeito a um domínio ou problema específico - o desemprego - faz do engajamento associativo uma forma de se tornar útil para a colectividade e assim assegurar a sua legitimação social e política em tanto que actores sociais capazes. Esta motivação é implicitamente uma resposta ao discurso dominante - de certa maneira paternalista e marginalizante - que considera os jovens como actores passivos, que intervêm pouco na solução dos problemas que os afectam e da sociedade no geral. Neste contexto, como se refere em alguma literatura, o engajamento associativo dos jovens torna evidente um processo de representação sociológica de sí, e apresenta-se como uma prática e abordagem estratégica que desenvolvem para ocupar um espaço na sociedade. 
Os jovens se associam também pela vontade que têm de criar e, neste caso, consolidar os laços sociais. Pela adesão nas associações, os jovens podem "conhecer [outros] jovens e podem abrir-se com eles". Fazer parte de uma associação significa "poder estar pessoalmente em contacto com os jovens... e poder manter laços com eles"; é também um sinal de "união entre os jovens", uma união necessária para ultrapassar "os obstáculos que não se podem resolver sozinho”. Neste sentido, a associação é apresentada como um viveiro de estruturação e consolidação de laços entre jovens numa tripla dimensão: afectiva, informativa e de orientação. Segundo os próprios jovens, engajar-se nas associações é uma maneira de encontrar "convivialidade" que se manifesta pelo "amor de uns para com os outros"; e significa também puder "informar-se" sobre numerosos assuntos que dizem respeito à sociedade. E como diz Sainsaulieu, o poder de constituição e consolidação que se opera pela associação, é uma resposta à situação dos próprios jovens pois ela permite construir a identidade, o reconhecimento pelos outros, a firmeza para consigo mesmo e portanto a capacidade de encarar o mundo (Sainsaulieu, 1996, p. 8).

A construção da identidade e a procura do reconhecimento perante os outros fazem do engajamento associativo dos jovens um gesto pelo qual eles procuram uma pertença a um grupo e rede sociais. Nesse sentido, aderir a uma asssociação é importante porque dá sentido à vida e permite se orientar para o futuro; pois é na condição de associados que os jovens se informam sobre que portas e oportunidades que se abrem para o mundo. Assim, a associação representa um espaço de sociabilidade rico em relações contextuais. Os laços que são construidos nas associações são de certa forma "rentáveis", porque cada pessoa nela encontrada abre para o jovem filiado um mundo feito de seus próprios conhecimentos, experiências e ideias. Neste sentido, na qualidade de associado e no seu percurso, o jovem terá efectuado uma aprendizagem a meio caminho entre a mobilização da rede e o desenvolvimento das competências individuais (Bidart, 1999, p. 15)

Finalmente, no discurso dos jovens, encontram-se motivações específicas e precisas sobre eles próprios. Existem os jovens que aderiram à associação para satisfazer o seu próprio prazer, assim como para materializar antigos sonhos; aqueles cuja motivação é o lazer e a procura de diversão; e ainda os que aderiram de maneira espontânea e voluntária para ocupar o seu tempo. Esta função de "espaço de evasão" que a associação desempenha, reside não só na oferta de actividades de entretenimento e lazer (como o desporto), mas também nas viagens que são efectuadas entre associados. São viagens que para além de que seriam insuportáveis a título pessoal, elas permitem aos jovens sair do seu enclave social e geográfico, o que lhes permite ao mesmo tempo alargar o seu repertório de experiências e ter novas referências para se orientar na vida.

\section{Papeis e dinâmicas implícitas das associações}

A literatura relativa ao fenómeno associativo em Moçambique aborda-o habitualmente de modo optimista e idealizado sobretudo em relação ao papel desempenhado por estes agrupamentos. No discurso político ou mesmo académico, por exemplo, as associações, a democracia e o desenvolvimento aparecem sempre associados. Multiplicaram-se textos que defendem o envolvimento de associações e de grupos diversos no processo da democratização, desenvolvimento e mesmo da boa governação do país. As associações têm a reputação de contribuir para o reforço dos princípios fundamentais da democracia, ao agir a favor da promoção e defesa dos direitos políticos e sociais das pessoas; elas são consideradas "escolas da cidadania" ou espaços do seu exercício através dos quais os seus membros exercem os seus direitos. (José e Monteiro 1995; Kulipossa, 1997). Cremos que, em determinados contextos, está-se perante uma relação demasiadamente mistificada, antes mesmo de se tornar realidade.

Considerar-se o papel das associações neste prisma somente serão visualizados os seus papéis explícitos. Porém, estes papéis explícitos já se inscrevem numa legitimidade afirmada e autoproclamada de todo um sector de organizações chamadas não governamentais. E esta legitimidade é apenas uma das representações simbólicas do associativismo. Para além do seu papel explícito, as associaçõs têm funções e papéis latentes. Os papéis implícitos das associações são aqueles que não estão formalmente formulados e trata-se de considerar o significado da associação para os jovens associados colocando em confrontação as motivações da adesão e o que eles próprios apresentam como "benefícios" obtidos por ser associado. Os dados de que se dispõe sugerem uma multiplicidade de motivações, 
de expectativas e, por consequência, de papéis que desempenham estes agrupamentos.

Das motivações identificadas pelo testemunho discursivo dos jovens, fez-se referência acima que as associações são um espaço onde os jovens encontram um emprego e/ou nele lutam contra o desemprego. 0 problema do desemprego e/ou do trabalho é crucial para os jovens na medida em que é através dele que estes fazem a entrada na vida adulta e o trabalho é também o fundamento e condição da reprodução da sociedade. Assim, ao se tornar um espaço de socialização pelo trabalho, a associação é e revela-se hoje importante porque cada vez mais as oportunidades de encontrar um emprego ou de trabalhar são muito difíceis e mesmo aleatórias, e também porque os riscos de exclusão social, quando não se tem emprego, são também cada vez mais presentes, mesmo ao nível familiar.

Como é que ocorre esta socialização pelo trabalho? Nessa procura de encontrar um ambiente profissional, a associação é uma espécie de estrutura de acolhimento para os jovens e contribue para diminuir ou parar com o seu desemprego de duas formas: por um lado, eles desenvolvem actividades criativas de emprego remunerado, assim como profissões e ofícios de que eles próprios se tornam o público alvo; por outro lado, é nas associações onde se pode transmitir o saber fazer e constituem um lugar privilegiado de aprendizagem, através de programas de formação e de capacitação oferecidos por instituições parceiras (seminários e debates inclusos); que estimulam, de certa maneira, as vocações e o sentido para o trabalho.

A experiência e a socialização pelo e para o trabalho são ainda centrais, não só porque o trabalho dá meios financeiros e materiais a partir dos quais se pode assegurar a nossa reprodução social, mas também porque o trabalho é a fonte do poder, do reconhecimento, do posicionamento social e da independência pessoal dos jovens em relação aos outros (Sainsaulieu, 1996). 0 voluntariado associativo substitui o trabalho e fornece elementos de aquisição de um estatuto e identidade social aos jovens desempregados, sobretudo num mundo onde o jovem é visto e confundido como o agente produtor da anomia social.

Por outro lado, as associações são vectores da formação do capital social dos jovens, mesmo se é um capital social fragmentado e individualizado. Engajados nas associações, os jovens participam na formação deste capital social fundado em motivações altruistas, humanitárias e éticas. Ao realizar actividades "direccionadas para os outros", ao querer "ser útil para a sociedade" e ao trazer a sua contribuição para "combater" ou "resolver os problemas que afectam a sociedade", os jovens fazem um investimento em objectivos e acções socialmente e moralmente valorizados. Isto ocorre porque cada acção realizada pela associação tem um valor acrescentado e constitui uma experiência e um conhecimento adquirido para aqueles que a realizam. Este valor acrescentado de competências traduz-se por um saber-fazer, um saber-falar e um saber-viver que são adquiridos ou de maneira informal (através de contactos frequentes que os jovens mantêm com os projectos que eles implementam) ou formal (através de workshops, seminários, debates e aulas de reforço das competências dadas pelos seus financiadores).

Através destas competências, os jovens associados têm acesso a uma certa "expertise"que eles esperam que seja válida para o seu projecto individual. As associações trazem experiência, profissionalismo e especialização e sobretudo são espaços de construção de um currículo vitae que será util no futuro. Ter a consciência da dimensão temporal nas expectativas é, neste caso, muito importante: os proveitos não são vistos nem a curto ou a médio prazo, mas a longo prazo.

$O$ facto de as organizações serem estruturas de acolhimento para a experimentação socioprofissional dos jovens faz das associações instâncias que desempenham o papel de espaços de preparação para o sucesso, para a mobilidade social e mesmo política dos seus associados. Aqui, a associação é uma fase transitória, uma estratégia, um meio para atingir uma finalidade, deliberada ou não. Os jovens associados não têm uma posição institucional adquirida e eles vêem-se muitas vezes em passagem e eles fazem da associação umas das etapas na sua trajectória social ascendente. Estas expectativas existem mais no domínio da formação. A quase totalidade dos jovens conta com as associações para realizar os seus sonhos, de poder um dia fazer o ensino superior, através da facilitação das bolsas de estudo disponibilizadas pelos doadores. Estas referências estão ao mesmo tempo ligadas ao papel que a educação e o ensino formal desempenham na mobilidade e sucesso social do indivíduo.

Existe uma diversidade de capitais que estes jovens trazem para fazer parte de uma associação e estes estão 
ligados à natureza das actividades que eles realizam. As actividades que os jovens realizam através de projectos associativos constituem deste modo categorias e bens sociais que são vistos, apreciados e valorizados. Aqui a associação é uma espécie de vitrina dos próprios jovens perante a sociedade. Para cada actividade realizada, eles são apreciados e valorizados e ganham alguma visibilidade em relação à colectividade. Neste sentido, a associação é um espaço de formação do capital simbólico. Este capital simbólico baseia-se no reconhecimento e na reputação (Bourdieu, 1994, p. 160). Os jovens são valorizados pelo que fazem e respondem às expectativas que a sociedade constroe sobre si.

Embora o capital simbólico esteja ligado ao grupo como tal, no sentido de comum a todos os membros da associação, na prática ele é privilégio explícito dos líderes e dirigentes das associações que o conservam e aumentam e dessa forma eles chegam a se distinguir e se diferenciar dos demais. A notoriedade e o prestígio que aqui se adquire transformam-se em conquistas e vantagens sociais que, seja como for, podem responder às expectativas colectivas e individuais dos jovens associados. Sem mesmo ter que calcular, os jovens ajustam implicitamente estes capitais na sua situação e contexto, feitos ao mesmo tempo de muitas privações e de uma grande vontade de vencer na vida. O capital simbólico é um benefício potencial que o líder pode na prática e em situações concretas rentabilizar para a sua mobilidade e ascensão sociopolítica (ser co-optado para cargos de natureza política, governamentais ou outras).

Para além do capital social e simbólico, as associações representam também espaços de acumulação do capital material. Por causa dos profundos desajustamentos sócioeconómicos e políticos conhecidos pelas sociedades africanas e que afectaram as práticas individuais e os imaginários sociais, a ascensão social vai juntamente e é valorizada com o sucesso material. Estas novas formas de acumulação se constrõem no interface do público e do privado, do local e do internacional, do formal e do informal e mesmo do lícito e do ilícito. Os jovens fazem das associações espaços de distribuição de riqueza que em princípio, é destinada à implementação dos seus projectos. A "rentabilidade" dos agrupamentos associativos manifesta-se também ao nível material e financeiro. Como eles próprios dizem saco vazio nunca fica em pé
A associação torna-se fonte de receitas de duas formas. Primeiro há associados que entraram só para trabalhar porque as associações desenvolvem actividades criadoras de emprego remunerado para eles próprios e para o seu público alvo. Estas situações de trabalho permitem aos jovens aceder aos meios financeiros e materiais a partir dos quais eles podem assegurar a sua própria reprodução social, dos "seus", assim como concretizar os seus projectos individuais. Em segundo lugar, as associações funcionam na base de projectos maioritariamente financiados por ONGs internacionais. É neste tipo de projectos que encontram as fontes de rendimento e a renda material e financeira em relação às quais as associações desempenham o papel de distribuidores. Neste contexto, quanto mais os jovens terão a capacidade de elaborar e montar projectos e endereçar aos financiadores para os "vender”, mais a associação acumulará fundos também. E em muitos dos casos, são os dirigentes das associações que privilegiam uma acomulação pessoal em detrimento da distribuição colectiva o que gera sempre conflitos.

No segundo caso, o projecto e o orçamento são verdadeiros instrumentos e objectos de estratégias colectivas e individuais. Colectivamente os projectos são uma fonte de receitas para os associados através de uma verdadeira "engenharia orçamental" que se opera para permitir uma distribuição da "renda" aos associados: "a nossa remuneração depende dos projectos; temos remuneração quando há um projecto no activo", dizem. Esta remuneração chamada "estimulante" ou "subsídio" faz-se ao nível das rúbricas orçamentais chamadas "despesas com o pessoal", "despesas administrativas" ou ainda "imprevistos".

Duas notas devem ser feitas a respeito desta enginharia.Primeiro, os subsídios ou "estimulantes" constituem verdadeiros salários para os jovens associados. Segundo, estas engenharias orçamentais não beneficiam todo o mundo. São sobretudo os membros executivos, fundadores e dirigentes da associação que saem a ganhar. Para os outros, os "membros ordinários" ou os "voluntários", no sentido restrito do termo, aproveitam quando há actividades específicas que exigem a deslocação para um lugar longíquo e por um período um pouco longo, durante a viagem. Nestes casos, os "estimulantes" são para apoiar nos custos de deslocação e para uma pequena refeição, entre outras despesas. 


\section{Concluindo}

A explosão das associações de jovens em Moçambique constituiu uma resposta às mudanças sócioeconómicas e políticas ocorridas nos finais dos anos 80 . Com estas mudanças, o jogo político foi se alterando e novos actores (para além do Estado) emergiram e participaram na vida pública. Estas mudanças simultaneamente internas e externas forneceram o quadro das possibilidades contextuais para o surgimento destas organizações.

A análise das motivações do engajamento em associações demonstrou que a dinâmica associativa de jovens mete em evidência relações complexas entre identidade, contexto, vida privada, vida pública e vida afectiva. Tendo surgido primeiro como pequenos círculos e redes de relações com vocação cultural e recreativa nas escolas e igrejas, estas redes foram se consolidando e se institucionalizando em agrupamentos associativos formalmente reconhecidos.

Considerados sempre como o futuro da sociedade e constantemente mobilizados a associarem-se para melhor servir a colectividade no presente, o engajamento de jovens em associações se apresenta como uma estratégia de regulação entre projectos pessoais e projectos colectivos. Engajar-se na associacão constitui uma etapa, um trampolim, um lugar de passagem, um laboratório de experimentação social, profissional ou mesmo política, para melhor enfrentar os desafios e incertezas do futuro. Neste sentido, elas constituem vectores de formação do capital social, simbólico e material dos jovens.

Contudo, fica por aprofundar em que medida a explosão de associações de jovens é signo de um movimento juvenil com objectivos sóciopoliticos comuns. Os dados de que se dispõe revelam que o explosão é mais resultado de estratégias de actores locais que souberam se adaptar a novos dados contextuais. Para além de serem muito plurais, o espaço das associações de jovens encontra-se muito fragmentado, menos coordenado e estruturado, agindo mais na lógica de competição e com défice de representatividade da maioria dos estratos de jovens.

\section{Referências}

BARTHELEMY, M. Associations, une nouvelle âge de participation sociale? Paris: Presses de Science Po, 2002.

BIDART, C. L'amitié, un lien social. Paris: La Découverte, 1997.

BIDART, C. Se lier et s'orienter: relations, réseaux, passages. Agora-Débats Jeunesses, Paris, v. 17, p. 7-17, 1999.

BOURDIEU, P. Raisons pratiques: sur la théorie de l'action. Paris: Seuil, 1994.

CAILLÉ, Alain. Don et association. In : Une seule solution, l'association? Socio-économie du fait associatif. La Revue du M.A.U.S.S, Paris, semestrielle n. 11, , p. $75^{-83}, 1^{\text {er }}$ Semestre 1998.

FAURE, Y.-A. Les ONG: de l'action à la recherche, de la compréhension à la banalisation. In : DELER, J.P. et al. ONG et développement: société, économie, politique. Paris : Karthala, 1988. p. 9-22.

JOSÉ, A.; MONTEIRO, A. ONG's: faces e contra faces na identidade civil moçambicana. Maputo: Centro de Estudos Africanos, 1995. (Colleção Nosso Chão, 5)

KULIPOSSA, F. P. Sociedade civil, ONG's e boa governação no processo de reformas das relações estado-sociedade em Moçambique: um quadro téorico, conceitual e empírico para debate. Maputo: Ministério da Administração Estatal/Programa de Reforma dos Orgãos Locais, 1997. (Texto de discussão, 2).

LAVILLE, Jean-Louis. Fait associatif et espace démocratique. In : Une seule solution, l'association? Socio-économie du fait associatif. La Revue $d u$ M.A.U.S.S. Paris, semestrielle n. 11, , p. 65-74, $1^{\mathrm{er}}$ Semestre 1998.

LAVILLE, J. L. ; SAINSAULIEU, R. Sociologie de l'association. Des organisations à l'épreuve du changement social. Paris: Desclée de Brouwer, 1997.

LOFORTE, A. Gênero e poder entre os Tsonga do sul de Moçambique. Lisboa: ISCTE, 1996. 
MANJANTE, N. B. Diagonóstico participativo do associativismo juvenil em Moçambique: suas práticas, ambiente institucional nas cidades de Maputo e Nampula. Maputo: LINK/Fórum de ONG's Nacionais e Estrangeiras, 2001.

OLIVIER DE SARDAN, J.-P. Ce que pourrait être un programme de recherche sur les ONG. In : DELER, J.-P. et al. ONG et développement: société, économie, politique. Paris : Karthala, 1988. p. 23-7.

PAIS, J. M. Culturas juvenis. Lisboa: Imprensa Nacional Casa da Moeda, 1993.

PERRINEAU, P. L'engagement politique : déclin ou mutation? Paris: FNSP, 1994.

ROUDET, B. (Dir.). Des jeunes et des associations. Paris: L'Harmattan, 1996.

WORMS, J .P. Jeunesse et engagement associatif. In : GILLET, J.-C. Les associations, des espaces entre utopies et pragmatismes. Bordeaux : Presses Universitaires de Bordeaux, 2001. p. 97-120. (Le territoire et ses acteurs) 